\title{
The Use of Syntax and Information Structure During Language Comprehension: Evidence From Structural Priming
}

\section{Citation}

Ziegler, Jayden, and Jesse Snedeker. "The Use of Syntax and Information Structure during Language Comprehension: Evidence from Structural Priming." Language, Cognition and Neuroscience 34, no. 3 (2019): 365-84.

\section{Permanent link}

http://nrs.harvard.edu/urn-3:HUL.InstRepos:38561556

\section{Terms of Use}

This article was downloaded from Harvard University's DASH repository, and is made available under the terms and conditions applicable to Open Access Policy Articles, as set forth at http:// nrs.harvard.edu/urn-3:HUL.InstRepos:dash.current.terms-of-use\#OAP

\section{Share Your Story}

The Harvard community has made this article openly available. Please share how this access benefits you. Submit a story. 
This is the authors' copy of the final unpublished version of this manuscript. The Version of Record is available at:

https://doi.org/10.1080/23273798.2018.1539757

Please cite as:

Ziegler, J., \& Snedeker, J. (2019). The use of syntax and information structure during language comprehension: Evidence from structural priming. Language, Cognition, and Neuroscience, 34(3), 365-384.

The use of syntax and information structure during language comprehension: Evidence from structural priming

Jayden Ziegler \& Jesse Snedeker

Department of Psychology, Harvard University

Jayden Ziegler (corresponding)

Dept. of Psychology

Harvard University

33 Kirkland St., Room 1180

Cambridge, MA 02138

(908) 548-3384

ziegler@g.harvard.edu 


\begin{abstract}
Structural priming in comprehension seems to be more variable than in production. Sometimes it occurs without lexical overlap, sometimes it does not. This raises questions about the use of abstract syntactic structure and how it varies across tasks. We use a visual-world eye-tracking judgment task and observe two kinds of priming effects. First, participants were more likely to switch to looking at the target referent immediately after the word when the syntactic structure of the target matched that of the prime. Second, participants also looked more to referents that could take on the thematic role that was in sentence-final position in the prime sentence, and thus in discourse focus. Critically, neither effect depended upon lexical overlap. Our results suggest that structural priming in comprehension manifests itself differently depending on situational demands, reflecting the activation of different levels of representation under different pressures. Keywords: language comprehension; structural priming; dative alternation; information structure; eye tracking
\end{abstract}




\section{Introduction}

Structural priming refers to the tendency for people to reuse previously encountered sentence structures (Bock, 1986; for reviews and meta-analysis, see Branigan, 2007; Branigan \& Pickering, 2017; Mahowald, James, Futrell, \& Gibson, 2016; Pickering \& Ferreira, 2008; Tooley \& Traxler, 2010; Traxler \& Tooley, 2012). For example, Bock (1986) found that speakers were more likely to describe an image using a double-object (DO) dative ("The man is reading the boy a story") after they've just heard another DO dative ("A rock star sold an undercover agent some cocaine") relative to after hearing a prepositional-object (PO) dative ("A rock star sold some cocaine to an undercover agent"), and vice versa. Crucially, we see a similar facilitation effect in comprehension, as indexed by, for example, faster reading times following matching vs. nonmatching sentence structures (e.g., Tooley \& Bock, 2014; Traxler \& Tooley, 2008), or predictive looking to a visual referent consistent with the structure of a preceding sentence (e.g., Arai, van Gompel, \& Scheepers, 2007; Thothathiri \& Snedeker, 2008a; see below).

In language production tasks, priming persists even when the verbs in the prime and target are different (as above; Pickering \& Branigan, 1998). We will refer to this form of priming as "abstract priming." The existence of abstract priming, among other things, has led researchers to conclude that the primary locus of structural priming in production is an abstract syntactic phrase structure (see, e.g., Branigan \& Pickering, 2017). ${ }^{1}$ Nevertheless, priming has also been shown to be greater with lexical overlap (e.g., Cleland \& Pickering, 2003; Pickering \& Branigan, 1998; Scheepers, Raffray, \& Myachykov, 2017). We will refer to priming that is dependent on lexical overlap as "lexicalized priming." In contrast to abstract priming, lexicalized priming is

\footnotetext{
${ }^{1}$ Throughout this paper, we follow the common practice of calling these effects syntactic. However, as we note in Section 1.1, most structural priming experiments, including our own, cannot distinguish between the priming of abstract phrase structure (NP-V-NP-NP vs. NP-V-NP-PP) and the priming of an abstract event structure (caused possession vs. caused motion).
} 
thought to index lexically-specific representations (e.g., structural chunks that incorporate the verb or links between the verb and structure; for discussion, see Branigan \& Pickering, 2017; though cf. Scheepers et al., 2017).

Curiously, in comprehension, abstract structural priming seems to be more variable. While some comprehension studies have found structural priming in the absence of lexical overlap (e.g., Arai \& Mazuka, 2014; Scheepers \& Crocker, 2004; Thothathiri \& Snedeker, 2008a/b; Segaert et al., 2013), others have found priming only when the verb in the prime and target are the same (e.g., Arai et al., 2007; Branigan et al., 2005; Tooley \& Bock, 2014; Tooley, Traxler, \& Swaab, 2009; for reviews and discussion, see Pickering \& Ferreira, 2008; Tooley \& Traxler, 2010; Traxler \& Tooley, 2012). In contrast, in production, abstract priming is consistently present (see, e.g., Mahowald et al., 2016; Pickering \& Ferreira, 2008).

Structural priming is believed to be an automatic result of using or constructing a given representation. Thus, if priming in comprehension is limited to sentences with the same verb, then it would suggest that more abstract structural representations are not constructed during comprehension and that we instead rely primarily on lexicalized representations. This would be broadly consistent with theories in which comprehension often occurs without a full syntactic analysis (e.g., Ferreira, Bailey, \& Ferraro, 2002; Levy, 2008b, 2011; Morgan, Keller, \& Steedman, 2010; Tabor, Galantucci, \& Richardson, 2004; Townsend \& Bever, 2001). If abstract structural priming is only present in some comprehension contexts and not others, then it would suggest that our use of lexicalized and abstract structure varies across contexts. This would open up questions about the nature of this flexibility and its function.

Structural priming in comprehension has been studied using a variety of different measures (e.g., acceptability judgments, picture matching, reading time, predictive eye 
movements, event-related potentials [ERPs], fMRI adaptation) and structures (reduced relatives, high-low attachment ambiguities, object-complement ambiguities, early vs. late closure syntactic ambiguities, passives, datives; for reviews, see Branigan \& Pickering, 2017; Tooley \& Traxler, 2010; Traxler \& Tooley, 2012). In most cases, however, we have just one data point for a given structure in a given paradigm. This makes it difficult to understand what factors lead to the presence or absence of abstract priming in comprehension. A notable exception is the visualworld eye-tracking paradigm (e.g., Altmann \& Kamide, 1999; Cooper, 1974; Tanenhaus, Spivey-Knowlton, Eberhard, \& Sedivy, 1995). Both Arai et al. (2007) and Thothathiri and Snedeker (2008a) used visual-world eye tracking with dative stimuli. Curiously, even though they were closely parallel in many ways, these studies yielded different results: Arai et al. (2007) found priming only when the verb was repeated from prime to target, while Thothathiri and Snedeker (2008a) found robust abstract priming effects.

However, each of these studies was peculiar in its own way. The visual displays in Arai et al. (2007) depicted a single event ensuring that the meaning of the unfolding sentence was predictable prior to it being spoken. In contrast, Thothathiri and Snedeker (2008a) asked participants to act out events with props. Thus, while their events were not predictable, the study introduced new demands (action planning) that are unusual for an online comprehension task. It's not clear how these design choices affected the observed patterns of results. In the experiments reported here, we remove these worrisome features to explore whether abstract dative priming occurs in the visual-world paradigm when the meaning of the sentence cannot be predicted ahead of time but there is no need to plan or execute an action. We hope this will help us understand these diverging data points and to draw broader conclusions about the role of the communication task in shaping language comprehension. 
In the remainder of this introduction, we first discuss key differences between the two dative constructions that could potentially contribute to priming. We then contrast the processes of comprehension and production to understand why the role of abstract syntax may vary. Next, we describe and evaluate the studies in Arai et al. (2007) and Thothathiri and Snedeker (2008a) in more detail to understand how tasks might interact with syntactic representation. Finally, we present the goals of the present study.

\subsection{Sources of dative priming}

In order to understand how priming might affect language comprehension, we first have to think about the two constructions we are using and how differences in their representations might contribute to priming. The dative alternation consists of the two constructions given in (1).

(1) a. The man threw [the dog] $]_{\text {NP-RECIPIENT }}[\text { the ball }]_{\text {NP-THEME }}=$ double-object (DO) b. The man threw [the ball $]_{\text {NP-THEME }}[\text { to the dog }]_{\text {PP-RECIPIENT }}=$ prepositional-object $(\mathrm{PO})$ These constructions differ in their surface syntactic phrase structure: DO datives have an NP-VNP-NP phrase structure, while PO datives have an NP-V-NP-PP structure. They also differ in how thematic roles are assigned to syntactic positions: DO datives have a recipient as their direct object and a theme as their second object, while PO datives have a theme as their direct object and a recipient as their oblique object. ${ }^{2}$ As a result of this difference in the ordering of roles, DO and PO datives also have different information structural properties. Sentences are typically structured with old, or given, information first and focused, or new, information last (e.g., Gundel, 1988). Thus, we might expect that the theme argument would be focused in a DO dative

\footnotetext{
${ }^{2}$ Following common practice, we use the term "theme" to refer to sentential arguments that move or change states, such as the non-recipient post-verbal argument in a dative sentence, although the exact definition is widely debated (see, e.g., Levin \& Rappaport Hovav, 2005; for further discussion, see Dowty, 1991).
} 
and the recipient argument would be focused in a PO dative. Finally, although DO and PO datives can be used to refer to many of the same events, they have been argued to have distinct conceptual representations (different event structures): DO datives have been said to describe caused possession events while PO datives are said to describe caused motion events (e.g., Goldberg, 1995; Harley, 2003).

Most of our understanding of how these different levels of representation contribute to dative priming has come from production studies. The canonical finding is that the use of DO primes results in more DO target productions while the use of PO primes results in more PO target productions (Bock, 1986; for meta-analysis, see Mahowald et al., 2016). In most cases, this priming could logically reflect any or all of the differences above. Nevertheless, this priming is typically attributed to syntactic phrase structure (e.g., Branigan, 2007; Branigan \& Pickering, 2017; Branigan, Pickering, Liversedge, Stewart, \& Urbach, 1995; Chang, Dell, \& Bock, 2006). When these variables can be disentangled, however, there is evidence for multiple sources of priming. For example, Ziegler, Snedeker, and Wittenberg (2018) found priming from idiom ("The boss gives his employee the boot") and light verb primes ("The mother gives the child a scolding") to compositional dative targets, suggesting that syntactic structure can prime even when thematic differences are present. However, priming was enhanced from compositional dative primes ("The boy gives his classmate a pen") to other compositional dative targets ("The waitress gives the man a glass"), suggesting that thematic structure also primes (see also, e.g., Chang, Bock, \& Goldberg, 2003; Hare \& Goldberg, 1999; Ziegler \& Snedeker, 2018).

Critically, there is no evidence that we know of for priming at the level of information structure in datives (though see Section 4.1 for evidence of information structural priming in other constructions). Abstract priming of dative information structure would be priming of a 
particular thematic role in an event independent of the noun that filled that role. For example, encountering a DO dative prime might shift your attention to the theme of the event (the lastmentioned noun). This might lead you to attend more to potential themes when you encounter new sentences. Information structural priming in datives could be hard to detect because it may result in effects that go in the opposite direction of the effects predicted by syntactic (or semantic) priming. For example, in a visual-world study, priming based on the syntax of a DO dative would lead to the expectation that the first post-verbal argument would be a recipient, potentially generating early looks to possible recipients. In contrast, priming of the information structure of a DO dative would lead to a global shift of attention to the theme of the prime utterance, potentially generating more looks to possible themes. If these two effects overlap in time, they could cancel each other out. Alternatively, these effects could have different temporal dynamics, which may have been overlooked in past work.

\subsection{Mechanics of comprehension}

As we mentioned above, structural priming effects in production standardly occur in the absence of lexical overlap, while structural priming effects in comprehension frequently occur only when the verb repeats from prime to target. To understand how priming might manifest itself differently in comprehension than in production, we have to think about the order in which the relevant representations are activated in each process, and the differences in the nature of incrementality between them. In production, we start from a speech plan (i.e., a message-level representation) and generate structures and words. Comprehension involves the same representations but with the opposite starting point—we begin with sounds, find words, and construct structures, resulting in an interpretation. The message, the highest-level representation, 
is typically not known to the comprehender, or at least not known in its entirety (or why speak). Conversely, the producer will most often know the message that she wishes to convey, the event structure she is encoding, before she knows the specific words she will say. As a result, the flow of information through the system, and the role of each representation (its duration and centrality), tends to be different during these two processes. It is reasonable to suppose that the message is a constant and enduring part of production and that abstract syntactic and semantic features of the message will be encoded independent of lexical choices to the degree that this is possible (recognizing that it will not always be possible). Thus, unsurprisingly, models of production typically involve the creation of syntactic structure prior to or in parallel with lexical choice (e.g., Bock \& Levelt, 1994; Chang et al., 2006; Garrett, 1980; Levelt, 1989; for review and discussion, see Bock \& Ferreira, 2014).

In contrast, our theories of comprehension are grounded in the observation that phonological information is incrementally converted into lexical information, with words playing a primary role in how higher-level structures are (re)constructed (e.g., Hale, 2001; Levy, 2008a, 2011; MacDonald, Pearlmutter, \& Seidenberg, 1994; Trueswell \& Tanenhaus, 1994). In fact, the logical dominance of lexical information has led many theorists to propose that comprehension can often proceed without the construction of abstract syntactic representations (e.g., Townsend \& Bever, 2001), or with abstract representations that are deficient, contradictory, or only locally coherent (e.g., Ferreira et al., 2002; Levy, 2008b, 2011; Morgan et al., 2010; Tabor et al., 2004).

This difference in the logical problem of comprehension and production suggests that priming might be quite different in the two processes. Specifically, we might expect to see more consistent and robust abstract priming in production and more lexicalized priming in comprehension. In fact, ten years ago, when it looked as if comprehension priming was purely 
lexically-based, the dominant theories explained it in precisely this way (see, e.g., Arai et al., 2007; Branigan, 2007; Carminati et al., 2008; Tooley et al., 2009; Traxler \& Tooley, 2008).

But, critically, these differences may also explain why priming is variable in comprehension. First, priming in comprehension may vary as a function of the degree to which the task leads participants to engage in subsequent production of the message they just understood. At the extreme, a task with a heavy memory load, a delay, or complex verbal instructions could result in self-directed speech or sub-vocal rehearsal (Pickering \& Ferreira, 2008; Pickering, McLean, \& Branigan, 2013; Tooley \& Traxler, 2010; see also Pickering \& Garrod, 2007). At lower demand levels, it seems conceivable that the production process might be partially engaged, resulting, for example, in lexical choices without phonological form (for a related hypothesis, see Townsend \& Bever, 2001). Second, abstract priming in comprehension could depend on the degree to which abstract syntactic (or semantic) structures are needed to mediate between the words and the intended message. If you have no idea what is going to be said, then you will need (on many hypotheses) to build a syntactic parse to link arguments to their thematic roles. If, however, you are pretty sure what the message will be, then you may simply monitor the words as they come in to make sure the list is consistent with the expected message. We return to this point in the Discussion.

\subsection{Comprehension priming in the visual world}

In the present work, we investigate structural priming in comprehension by building upon two prior visual-world studies: Arai et al. (2007) and Thothathiri and Snedeker (2008a). These two studies are parallel in many respects. First, they both use the dative alternation in English. Second, they both use the visual-world paradigm. Finally, they both use predictive eye 
movements to measure language processing, relying on the same linking hypothesis that participants will begin to look at the argument that they expect in the first post-verbal position shortly after verb offset.

In a typical structural priming experiment, participants first encounter a prime sentence, either visually or orally (and in some cases repeat it back to the experimenter), and are then tested on whether that structure influences their subsequent behavior. In production, this is often assessed in terms of which structure they produce to describe a target picture or animation. In comprehension, it can include such measures as reaction times while reading, ERPs, and predictive eye movements. The visual-world paradigm makes use of predictive eye movements. The question becomes: Will participants use the structure of the prime sentence to predict the identity of an upcoming referent of a target sentence (and therefore look toward it) before that target sentence has disambiguated what the referent is going to be? If priming temporarily biases the internal generative model toward some structures over others (say, DOs over POs), this could lead comprehenders on subsequent sentences to build a prime-consistent parse and thus anticipate (i.e., predict) the upcoming referent (recipient) prior to actually hearing it. In this regard, comprehension priming (especially as measured by predictive eye movements) can be thought of as a consequence of prediction.

Despite their similarities, however, the experiments in Arai et al. (2007) and Thothathiri and Snedeker (2008a) differed radically in their data patterns: Arai et al. (2007) observed priming only when the verb was repeated from prime to target, while Thothathiri and Snedeker (2008a) only looked for and found abstract priming. Critically, each of these studies has an unusual feature which might account for the findings. Below, we discuss these two studies in more detail. 


\subsubsection{Arai, Van Gompel, and Scheepers (2007)}

Arai et al. (2007) included two experiments, one in which all verbs were repeated from prime to target and one in which they were not. On each target trial, participants viewed visual displays that consisted of an agent (e.g., pirate), a recipient (e.g., princess), and a theme (e.g., necklace) while hearing a target dative sentence (e.g., "The pirate will send the princess the necklace"). Critically, in this study, participants performed no other task beyond passively viewing the displays while listening to the sentences. In the same-verb experiment, there was a clear priming effect. Shortly after hearing the verb (send), looks to the recipient and theme differed depending on the prime sentence: There were more looks to the princess following a DO dative prime (e.g., "The assassin will send the dictator the parcel") and more looks to the necklace following a PO dative prime (e.g., "The assassin will send the parcel to the dictator"; see also Carminati et al., 2008). Critically, this priming was absent in the second experiment in which the prime and target had different verbs. This study suggests that, during comprehension, only lexicalized structural representations are primed.

One critique of this study, however, is that its visual displays were highly constraining such that only a single interpretation was possible. Specifically, in these experiments, the picture included only the three critical entities. Thus, once the agent and verb were identified, the rest of the event could be accurately inferred (i.e., if the pirate is giving, he must be giving the necklace to the princess; see Section 4.3). This may have reduced the need for participants to continue actively constructing a syntactic structure or thematic grid in order to arrive at the intended message - after all, the post-verbal arguments contained no new information. As a result, participants in Arai et al. (2007) may have processed the prime sentences more shallowly, 
comparing the lexical content to the predicted message. On many theories of priming, focused processing of lexical content would be expected to increase lexicalized but not abstract priming (e.g., Chang et al., 2006; Scheepers et al., 2017). This feature of Arai et al.'s (2007) study is unusual for comprehension experiments. While listeners may sometimes know what the speaker is going to say, our theories of comprehension have typically been based on tasks and contexts where the comprehender must actively interpret what is being said.

\subsubsection{Thothathiri and Snedeker (2008a)}

Thothathiri and Snedeker's (2008a) experiments tested priming across verbs. In their task, the visual displays consisted of four toys on a physical stage: two animate animals and two inanimate objects. Participants listened to dative sentences that were momentarily ambiguous at the onset of the first noun. For example, participants heard "Show the hor..." in the context of a dog, a horse, a book, and a horn. Two of the items were phonological matches to the initial part of the first noun (e.g., horse and horn), making them both candidate referents. In this study, after hearing each sentence, participants acted out the instructions using the toys in front of them (e.g., showing the horse the book). Participants looked reliably more to the potential recipient (e.g., the horse) when primed first with a DO dative, while they looked more to the potential recipient (e.g., the horn) following a PO dative. This priming occurred even though the verbs were different across primes and targets.

In contrast to Arai et al. (2007), the events to be enacted in Thothathiri and Snedeker (2008a) were far less predictable from the scene alone: The visual displays afforded 10 possible ditransitive events consistent with each verb rather than just one (4 with a single recipient and single theme, 2 with a single recipient and two themes, 2 with two recipients and a single theme, 
and 2 with two recipients and two themes). Consequently, participants could not anticipate the correct event prior to hearing each sentence. However, the results of Thothathiri and Snedeker (2008a) are difficult to interpret because they used an unusual task (i.e., the act-out task) which may fail to generalize. It has been argued that abstract priming in comprehension is most robust in tasks that involve more active engagement and thus might require deeper processing of the sentence (for discussion, see Carminati et al., 2008; Tooley \& Bock, 2014; Thothathiri \& Snedeker, 2008a). Under more demanding conditions, participants may be more likely to engage in sub-vocal rehearsal, internally repeating the sentence as they carry out the task (Pickering \& Ferreira, 2008; Pickering, McLean, \& Branigan, 2013; Tooley \& Traxler, 2010; see also Pickering \& Garrod, 2007). In other words, participants in Thothathiri and Snedeker (2008a) presumably needed to hold the sentence in memory as they planned their action. To do this, they may have silently repeated the sentence to themselves, resulting in the robust abstract priming observed in standard production tasks.

\subsection{Current study}

The goal of the present study was to improve upon the experiments in Arai et al. (2007) and Thothathiri and Snedeker (2008a), using the same measure and same constructions. In doing so, we hope to gain a better understanding of the factors that influence when abstract priming effects will emerge in comprehension. To do this, we used visual displays based on those used by Thothathiri and Snedeker (2008a). But instead of asking participants to follow the instructions, we showed them videos of two events after they heard each sentence, and we asked them which one matched the utterance they had heard. This design ensures that (1) the events cannot be inferred prior to hearing the full sentence (contra Arai et al., 2007), and (2) any priming effects 
we see cannot be due to the demands of planning or executing an action (contra Thothathiri \& Snedeker, 2008a).

In the experiments reported here, we manipulate whether the prime has a DO or PO structure (within subjects), whether the target has a DO or PO structure (within subjects), and whether the verb repeats from prime to target (between subjects). Note that we could expect priming to have effects at two different points of the incremental comprehension process: (1) Priming could affect prediction prior to encountering a word (see Section 1.3 above), and (2) priming could affect the integration of a word when we encounter it depending on the degree to which we expected it. Following Arai et al. (2007) and Thothathiri and Snedeker (2008a), we went into the experiment expecting to find predictive effects.

Critically, if abstract priming is present, we expect that participants will show priming patterns that are consistent in the within-verb and between-verb conditions. Specifically, following a DO dative prime, participants should look more to a possible recipient than theme, and vice versa following a PO prime, independent of whether the target sentence is a DO or PO. This should occur both when the verb repeats from prime to target and when it does not. Conversely, if priming in comprehension relies completely on lexicalized representations, then we expect priming only in the context of verb overlap. Finally, if both forms of priming are present, then we expect priming in both cases but that priming will be greater with verb overlap than without (e.g., Cleland \& Pickering, 2003; Pickering \& Branigan, 1998; Scheepers et al., 2017).

\section{Experiment 1}

\subsection{Methods}




\subsubsection{Participants}

72 native English speakers from Harvard University and the greater Boston area participated in Experiment 1 (40 female, 32 male; mean age $=28, \mathrm{SD}=14$, range $=18-61,3$ ages unknown). All participants provided written consent prior to participating and received course credit or $\$ 5$ for their participation.

\subsubsection{Materials}

There were 8 critical trials interspersed with 8 filler trials, for a total of 16 trials. Critical trials consisted of a sequence of two prime sentences followed by a target sentence, and filler trials consisted of three transitive sentences. Prime and target sentences contained one of eight alternating dative verbs (bring, feed, give, hand, pass, send, show, throw) in either the DO or PO construction (e.g., DO: "Now, he's gonna feed the baby the apple"; PO: "Now, he's gonna feed the bagel to the girl'). Each dative verb appeared once as a target and twice as primes. For half of the participants, the dative verbs used in prime sentences were identical to those in the subsequent target sentences (Same Verb; e.g., bring-bring-bring); for the other half of participants, three different dative verbs were used across each prime-prime-target triad (Different Verbs; e.g., send-pass-bring). Recipients were always animate, and themes were always inanimate. All sentences were normed on Amazon Mechanical Turk for naturalness. Filler sentences contained either one- or two-object direct objects (e.g., one: 'Now, he's gonna bite the donut"; two: "Now, he's gonna break the plate and the jar"). (For a full list of all prime and target sentences, see Supplementary Material.)

Sentences were paired with corresponding visual displays of four items, arranged in quadrants (Fig. 1). The four items consisted of cartoon images of two animate characters 
(humans or animals) and two inanimate objects. On target sentences, the set of accompanying items displayed on the screen contained two items that were phonological matches on the initial part of the first noun (e.g., ba...). One was a possible animate recipient (e.g., baby), while the other was a possible inanimate theme (e.g., bagel). We were interested in how much participants would look to each of these two items upon hearing the first noun, as an indication of which syntactic frame they were expecting to encounter. Specifically, participants primed with DO sentences should look more to the plausible target animate character (e.g., baby), reflecting the syntactic expectation for the first object in DO constructions to be the recipient, while participants primed with PO sentences should look more to the plausible target inanimate object (e.g., bagel), reflecting the expectation for the first object in PO constructions to be the theme. The positioning of items was counterbalanced across prime and target sentences, such that each of the target referent item, phonological competitor item, and remaining animate and inanimate distractor items appeared a roughly equal number of times in all four quadrants.
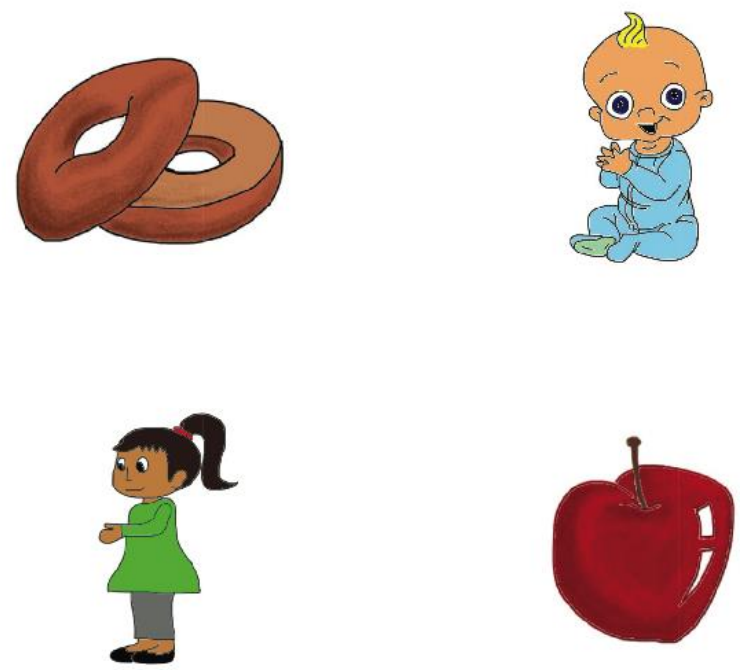
Figure 1. Example visual display. Target trials contained two items with similar phonological onsets (e.g., baby and bagel).

The stimulus set was presented as an extended narrative about a single character, John. Participants were introduced to John and told they were going to hear about some of John's favorite activities. Each sentence began with the pronoun he, referring back to John, and each animation (see below) included John as the agent.

All sentences were prerecorded by an adult male native English speaker (first author) and presented to participants over speakers. To control for any prosodic differences between the two dative constructions, target sentences (but not prime sentences) were spliced, such that half of the PO target sentences had DO target sentence beginnings (through to the first vowel of the first post-verbal noun; e.g., "Now, he's gonna feed the ba...”), and half of the DO target sentences had PO target sentence beginnings. The resulting set of target sentences averaged 3.4 seconds in length; the first post-verbal noun (N1) occurred $\sim 447.5 \mathrm{~ms}$ after the verb and $\sim 1132.5 \mathrm{~ms}$ before the second post-verbal noun (N2).

To verify that our splicing didn't create any artifacts in the audio recordings that might influence participants' behavior, we administered a norming task on Amazon Mechanical Turk. We asked 21 native English speakers ( 5 female, 16 male; mean age $=31, \mathrm{SD}=8$, range $=22-52$ ) to rate the quality of each of 17 different audio files on a scale from 1 (very unnatural) to 7 (very natural). Each participant rated 8 target sentences (some of which were spliced and some of which were not), 4 prime sentences (all non-spliced), and 5 baseline sentences (with splicing artifacts that were deliberately created). There were no differences in naturalness ratings among our spliced targets $($ mean $=5.49, \mathrm{SD}=.64)$, non-spliced targets $($ mean $=5.66, \mathrm{SD}=.89)$, and 
primes $($ mean $=5.70, \mathrm{SD}=1.10)$, all $p \mathrm{~s}>.33 .{ }^{3}$ In contrast, our baseline sentences were rated as considerably less natural $($ mean $=3.11, \mathrm{SD}=1.66)$.

\subsubsection{Procedure}

Participants listened to the prerecorded sentences while viewing and attending to the quadrant items on a computer screen. Prior to each sentence, the items were introduced sequentially (from quadrant 1 to quadrant 4), and an audio recording labeled each item as it appeared (e.g., "This is a baby"). Due to the nature of the counterbalancing in our visual displays, this meant that there was no systematic relationship between the order in which an item was introduced and whether or not it was animate, inanimate, the target referent item, a distractor item, or otherwise. Once the items were on the screen, a fixation cross appeared for $500 \mathrm{~ms}$, after which the sentence was played automatically. The items remained on the screen for $500 \mathrm{~ms}$ after the sentence ended. We tracked participants' eye movements to the four quadrant images as they listened to the sentences being played.

After each sentence, participants watched a short animated video. The event in the video either matched the immediately preceding sentence, or it did not, and participants were asked to indicate their selection by touching the screen (happy green smiley face for "match" and sad red frowny face for “mismatch"). Accuracy on this match task was very high (98\%).

The experiment began with four practice trials to allow participants to familiarize themselves with the task.

\footnotetext{
${ }^{3}$ For this analysis, we entered Sentence Type (Spliced target, Non-spliced target, Prime) as an effect-coded fixed effect into a linear mixed-effects model (lme4 package) in R, with random intercepts for participant and item and a random slope for Sentence Type within participants.
} 
Stimulus presentation was administered using E-Prime (Psychology Software Tools, Pittsburgh, PA), and eye movements were recorded on a Tobii eye tracker (Tobii Group, Sweden) that sampled at $60 \mathrm{~Hz}$ (i.e., recording participants' gazes every $16.6 \mathrm{~ms}$ ).

\subsubsection{Design}

The study used a $2 \times 2 \times 2$ mixed design, with Verb Match (Same Verb vs. Different Verbs) as a between-subjects variable, and Prime Type (DO vs. PO) and Target Type (DO vs. PO) as withinsubjects variables. Participants were randomly assigned to one of eight ordered lists, four in the Same Verb condition and four in the Different Verbs condition. Target Type and target sentence behavioral response (correct/incorrect) were counterbalanced across lists.

\subsection{Analysis}

\subsubsection{Justification}

In the previous visual-world studies, priming was assessed by measuring the proportion of looks to the potential recipient or theme in the period immediately after the verb or first noun, prior to phonological disambiguation of the intended referent (e.g., Arai et al., 2007; Thothathiri \& Snedeker, 2008a). This variable is intended to capture prediction of the upcoming referent given the information in the word onset. The assumption is that any systematic preference during this time window will reflect predictive processing of the noun based on the verb and prior prime sentence (see Section 1.3). Critically, these analyses assume that there are no earlier differences in looks to the referents that might interfere with, or masquerade as, predictive processing. For example, if dative structures highlight the role of the second post-verbal argument and this 
information structural preference persists across trials, then we might expect to see baseline differences in looks to potential recipients and themes before the noun or even the verb.

There were no baseline differences of this kind in Thothathiri and Snedeker (2008a). For this reason, we initially planned to use the same variable and analysis that they had used. This plan fell through, however, when we discovered an enormous and interesting priming effect in the baseline window, discussed below, which we interpret as indexing prediction at the level of information structure. These baseline differences make analyses of looking proportions in the subsequent windows uninterpretable. A statistically reliable downstream difference in looking time could reflect the persistence of the information structural prediction, while a null effect could result from a substantial shift in looks triggered by the noun, working against this earlier effect.

For this reason, we shifted the focus of our analyses to how well participants integrated the information in the sentence given the priming condition they had experienced. The hypothesis here is that if the prime structure is consistent with the target structure, we should get more shifts to the correct object. Note that this variable does not measure prediction but instead measures the speed of uptake for downstream information. Consequently, we focused on two time windows that are later than those used in the past visual-world studies. Our first time window corresponded to the 400-800 ms region following the onset of the first post-verbal noun (N1), which is roughly the point at which it has been phonologically disambiguated. Our second time window corresponded to the $0-400 \mathrm{~ms}$ region following the onset of the second post-verbal noun (N2; all reported time windows were corrected by $200 \mathrm{~ms}$ for saccade planning; Matin, Shao, \& Boff, 1993). In this respect, our analysis more closely parallels the analyses used in comprehension priming work involving reactive processing, in which participants are tested on 
how they make use of the information they've been given or how their processing profile changes after they've encountered the critical target sentence, or a portion thereof (e.g., picture selection, self-paced reading, ERPs, etc.).

Given the post hoc nature of this analysis, any effects that we find should be replicated before we draw strong conclusions. This is done in Experiment 2.

\subsubsection{Implementation}

The eye-tracking data were time-locked to the onset of the first post-verbal noun (N1) for the baseline and N1 regions and to the onset of the second post-verbal noun (N2) for the N2 region, and then averaged into $100 \mathrm{~ms}$ time bins spanning the entirety of each sentence. Only eye movements for target sentences were included in the analysis. No trials were excluded.

For all time windows and dependent measures, we used logistic mixed-effects models (Baayen, Davidson, \& Bates, 2008; Jaeger, 2008) in the lme4 package in R (Bates, 2010), with Prime Type (DO vs. PO), Target Type (DO vs. PO), Verb Match (Same Verb vs. Different Verbs), and their interactions as fixed effects. We used the maximal random effects structure appropriate for this experimental design (Barr, Levy, Scheepers, \& Tily, 2013), including random slopes for Prime Type, Target Type, and their interaction within participants and for Prime Type, Verb Match, and their interaction within items (verbs). All fixed effects were effect coded, with the first listed level of each variable coded as 1 and the second as -1 . Thus, the main effects in these analyses can be interpreted as if they were ANOVAs. 


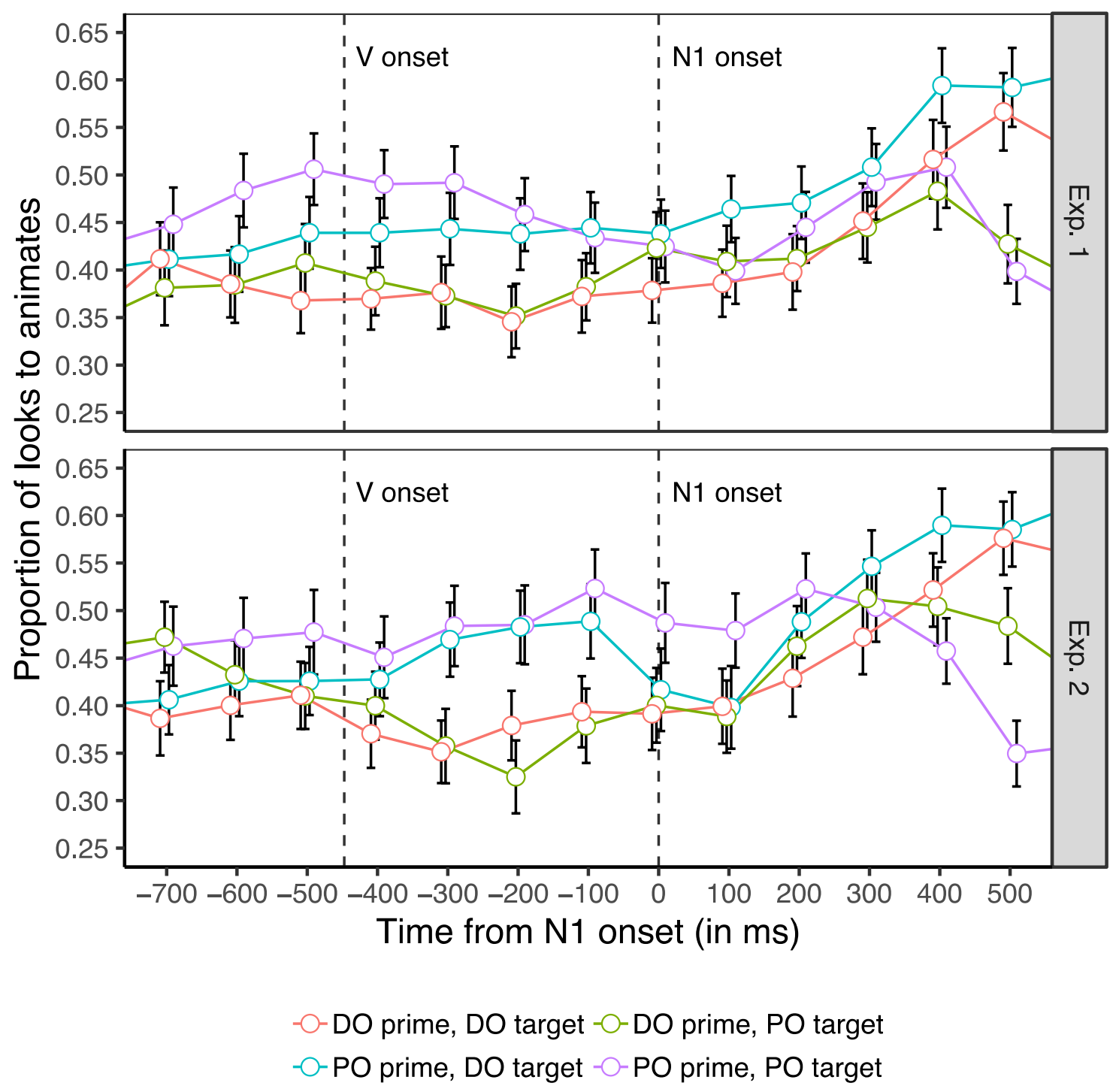

Figure 2. Average looks to animate referents in baseline (verb) region in Exps. 1 and 2 by Prime Type and Target Type. Visual inspection of the eye-tracking data revealed differences in looking preferences to animate vs. inanimate referents prior to N1 onset, apparently driven by Prime Type. Dotted lines represent V onset and N1 onset, respectively (corrected for saccade planning). Error bars reflect by-subject standard errors. $\mathrm{V}=$ verb; $\mathrm{N} 1$ = first post-verbal noun.

\subsection{Results and discussion}




\subsubsection{Baseline region}

Visual inspection of the eye-tracking data revealed differences in looking preferences to animate vs. inanimate referents prior to the onset of the first post-verbal noun (N1), apparently driven by Prime Type (Fig. 2). To verify this impression, we measured animate preference as our dependent variable: a binary measure indicating whether participants looked more at the animate referents or the inanimate referents during a given time window. This measure best captures the underlying distribution of our data. While our eye tracker samples gaze 60 times a second, people typically make only a couple saccades a second. Consequently, in a short time window, most participants will only fixate one of the objects, and thus any measure of fixation proportion within that window is essentially binary. To calculate animate preference, we averaged looks to either of the two animate referents in the $500 \mathrm{~ms}$ time window immediately preceding N1 onset (-500-0 ms), which corresponds roughly to the span of time from verb onset to N1 onset (see above). If this value exceeded 0.5 , animate preference was 1 . If it was less than 0.5 , then animate preference was 0 . If participants looked at both objects equally during the time window, then the trial was coded as NA and excluded from the analysis. In presenting the results (for descriptive purposes), we have aggregated over both participants and items.

The model revealed a significant main effect of Prime Type, $\beta=-.27(\mathrm{SE}=.12), z=-2.25$, $p=.02$, such that participants looked significantly more to animate referents following PO primes (44\%) relative to DO primes (33\%; Fig. 3). ${ }^{4}$ We found no other main effects or interactions. Importantly, this pattern of results is opposite what we would expect on the basis of syntactic prediction (and the timing of the effect is earlier than what we would expect on the

\footnotetext{
${ }^{4}$ In a post hoc analysis, we ran the same model on an even earlier time window (from -1000 to -500 ms) corresponding to roughly the span of time from subject onset (he) to verb onset. Effects were in the same direction (in both experiments) but not significant.
} 
basis of the prior studies). In particular, if participants were guided by the syntactic structure of the prime sentence in this early time window, then we should expect to see more looks to possible animate recipient arguments following DO primes and to possible inanimate theme arguments following PO primes. Instead, the observed effect is consistent with priming at the level of information structure. The final argument of a sentence is more likely to be new information (Gundel, 1988). It is also often given default stress and is frequently heavier in terms of both its phonological form and its semantic content (Gundel, 1988; Quirk, Greenbaum, Leech, \& Svartvik, 1972). Finally, by virtue of being at the end of the sentence, it benefits from recency effects, making it more memorable (Deese \& Kaufman, 1957). All of these factors conspire to draw attention to the inanimate themes of the DO sentences and the animate recipients of the PO sentences. To the extent that this contrast in themes vs. recipients persists across trials, it could drive attention toward other objects that could fulfill the same functions on the target trials.

Critically, there was no Prime Type by Verb Match interaction in this baseline region, suggesting that the information structural effect was independent of verb overlap. Notice that while this form of priming was unpredicted, it is another kind of abstract priming, and thus this finding demonstrates that we can detect such abstract effects in the visual world without the actout task (cf. Arai et al., 2007). 


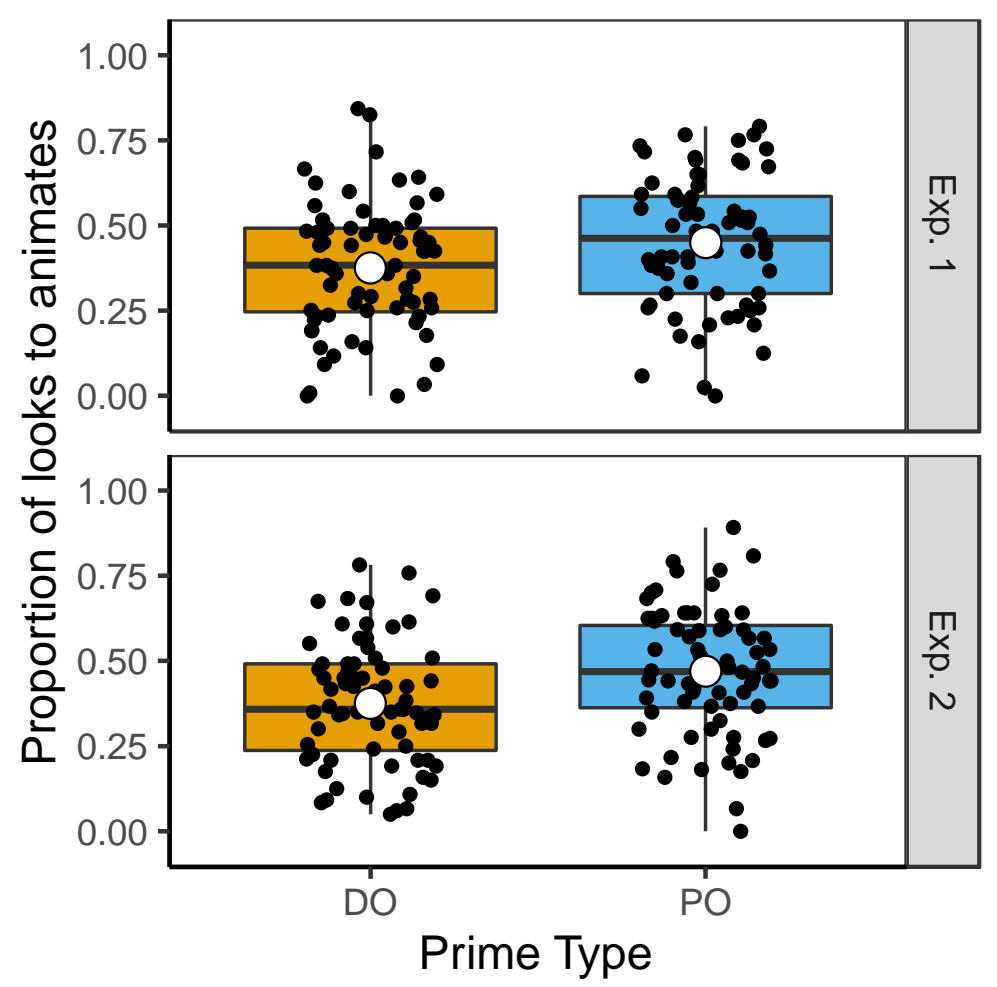

Figure 3. Average looks to animate referents in baseline (verb) region in Exps. 1 and 2 by Prime Type. Participants looked more to animate referents following PO primes relative to DO primes.

\subsubsection{First noun (N1) region ${ }^{5}$}

To operationalize our integration measure, we switched from measuring proportions of looks to measuring shifts in gaze (e.g., Fernald, Zangl, Portillo, \& Marchman, 2008). Specifically, data for a given trial were included in the analysis only if the participant was not already looking at the target referent, whether animate or inanimate (by Target Type), in the frame immediately preceding the time window of interest. Then, if at any time during that time window the

\footnotetext{
${ }^{5} \mathrm{We}$ also ran this analysis on the same region of phonological ambiguity $(0-400 \mathrm{~ms}$ post-N1 onset $)$ in Thothathiri and Snedeker (2008a). However, there were no effects involving Prime Type in this window (in either experiment), suggesting, perhaps, that any shifts based on the priming of syntax were cancelled out by shifts generated on the basis of information structural priming.
} 
participant switched to looking at the target, the trial was coded as 1, otherwise it was coded as $0 .{ }^{6}$ Thus, for DO targets in the first noun (N1) time window, trials were included only if the participant was not already looking at the target animate referent (e.g., baby) by $400 \mathrm{~ms}$. They were then coded as 1 if the participant looked to that character at any time between 400 and 800 ms, and as 0 otherwise. For PO targets in this window, trials were included only if the participant wasn't already looking at the target inanimate object (e.g., bagel) by $400 \mathrm{~ms}$, and were coded as 1 if the participant switched to looking at it at any time during the window, and 0 otherwise. As before, in presenting the results (for descriptive purposes), we have aggregated over both participants and items.

The model revealed a marginal Prime Type by Target Type interaction, $\beta=.19(\mathrm{SE}=.11)$, $z=1.69, p=.09$, such that participants switched to looking at the target display item more for consistent (DO-DO: 54\%; PO-PO: 60\%) than for inconsistent (DO-PO: 51\%; PO-DO: 47\%) prime-target sequences (Fig. 4). Thus, when targets matched their primes, participants were better able to integrate the information they were hearing than when targets and primes mismatched. However, the three-way interaction was not significant, $\beta=-.11(\mathrm{SE}=.11), z=-.99$, $p=.32$, such that whether or not the verb overlapped from prime to target did not modulate this priming. We therefore have no evidence to suggest that this marginal effect depends on verb overlap.

This is consistent with priming on the basis of syntax. What makes the PO structures, for example, in the primes and targets consistent is that they share a syntactic phrase structure (NPV-NP-PP). Accordingly, if participants build up expectations that subsequent sentences should

\footnotetext{
${ }^{6}$ We describe these effects as "switches" in order to indicate a change in the object of fixation from one referent to another, whereas the more traditional terms "saccade" and "eye movement" can also refer to changes in fixation within a single referent.
} 
have the same structure, then they should be better at incorporating the incoming information on the basis of this expectation, leading to more switches to the correct target. Conversely, when the target sentence's structure mismatches that of the prime's, participants' expectations will be violated, making it harder to incorporate the upcoming information because of the need to reevaluate the structure of the incoming sentence. This slow-down results in relatively fewer switches to the target within the same time window. Crucially, these results, if robust and replicable, appear to reflect abstract priming — as they are not tied to individual lexical itemsdespite the less hands-on task (cf. Arai et al., 2007).

\subsubsection{Second noun (N2) region}

Switches to the target in the second noun (N2) time window, spanning 0-400 ms post-N2 onset, were coded in the same way as above, though with $\mathrm{N} 2$ in each sentence (e.g., apple, girl) as the target instead of $\mathrm{N} 1$.

Within this region, we found a significant Prime Type by Target Type interaction, $\beta=.29(\mathrm{SE}=.12), z=2.44, p=.01$, such that participants switched to looking at the target display item more reliably for consistent (DO-DO: 64\%; PO-PO: 56\%) than for inconsistent (DO-PO: 51\%; PO-DO: 42\%) prime-target sequences (Fig. 4).

Recall that one question we walked in with was whether priming would be primarily mediated by lexically-specific representations. If that were so, we should have expected to see a significant three-way interaction, such that the Prime Type by Target Type effect was reliable only for the Same Verb but not Different Verbs condition. However, as before, the three-way interaction was not significant, $\beta=-.05(\mathrm{SE}=.11), z=-.42, p=.68$, suggesting that this effect is not lexically mediated. 


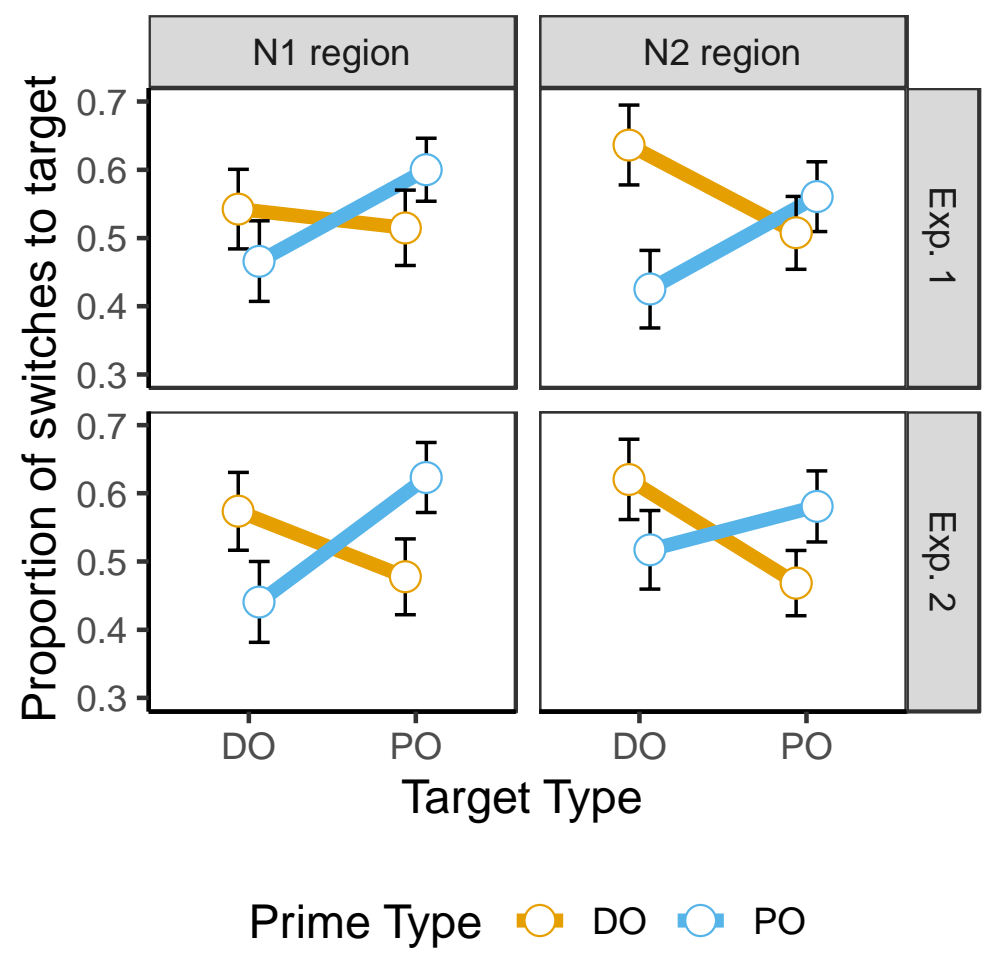

Figure 4. Prime Type by Target Type interactions in N1 and N2 regions in Exps. 1 and 2.

Participants switched to looking at the expected display item more for consistent (DO-DO, POPO) than for inconsistent (DO-PO, PO-DO) prime-target sequences. Error bars reflect by-subject standard errors. $\mathrm{N} 1$ = first post-verbal noun; $\mathrm{N} 2$ = second post-verbal noun .

\section{Experiment 2}

Because of the post hoc nature of our analyses above, we chose to replicate them on a new set of data.

\subsection{Methods}

\subsubsection{Participants}


72 additional native English speakers from Harvard University and the greater Boston area participated in Experiment 2 (39 female, 33 male; mean age $=24, \mathrm{SD}=10$, range $=16-60,1$ age unknown). All participants provided written consent prior to participating and received course credit or $\$ 5$ for their participation.

\subsubsection{Materials and procedure}

Experiment 2 was a direct replication of Exp. 1. Accuracy on the match task was very high $(99 \%)$.

\subsection{Results}

Six trials $(1 \%)$ were excluded from this analysis due to excessive track loss. The results of both experiments are summarized, side-by-side, in Table 1.

\subsubsection{Baseline region}

In the eye-tracking data, we found the same baseline preference pattern as in Exp. 1 (Fig. 2).

Specifically, participants looked significantly more to animates following PO primes (46\%) than following DO primes (34\%) in the $500 \mathrm{~ms}$ time window pre-N1 onset $(-500-0 \mathrm{~ms}), \beta=-$ $.26(\mathrm{SE}=.12), z=-2.22, p=.03$ (Fig. 3). This initial model yielded no other main effects or interactions.

\subsubsection{First noun (N1) region}

In the 400-800 ms post-N1 time window, the model revealed a significant Prime Type by Target Type interaction, $\beta=.35(\mathrm{SE}=.12), z=2.79, p=.01$, such that participants switched to looking at the 
target item more reliably for consistent (DO-DO: 57\%; PO-PO: 62\%) than for inconsistent (DOPO: 48\%; PO-DO: 44\%) prime-target sequences (Fig. 4). The model also revealed a significant Verb Match by Target Type interaction, $\beta=.27(\mathrm{SE}=.13), z=2.10, p=.04$, such that participants switched to the target more for DOs (52\%) than for POs $(44 \%)$ in the Same Verb condition and more for POs $(66 \%)$ than for DOs $(52 \%)$ in the Different Verbs condition. There is no clear theoretical interpretation of this pattern that we know of, and it is independent of priming. Thus, we do not discuss if further.

\subsubsection{Second noun (N2) region}

Finally, the switch-to-target analysis in the 0-400 ms time window following N2 onset also revealed a significant Prime Type by Target Type interaction, $\beta=.28(\mathrm{SE}=.12), z=2.31, p=.02$, such that, as before, participants switched to looking at the target item more reliably for consistent (DO-DO: 62\%; PO-PO: 58\%) than for inconsistent (DO-PO: 47\%; PO-DO: 52\%) prime-target sequences (Fig. 4).

Table 1. Results from Exps. 1 and 2.

\begin{tabular}{|c|c|c|c|c|c|}
\hline \multirow[t]{2}{*}{$\begin{array}{c}\text { Time } \\
\text { window }\end{array}$} & \multirow[t]{2}{*}{ DV } & \multirow[t]{2}{*}{ Critical effect } & \multicolumn{2}{|c|}{$\begin{array}{l}\text { Result (p- } \\
\text { value) }\end{array}$} & \multirow[t]{2}{*}{$\begin{array}{c}\text { What priming } \\
\text { reflects? }\end{array}$} \\
\hline & & & $\begin{array}{c}\text { Exp. } \\
1\end{array}$ & $\begin{array}{c}\text { Exp. } \\
2\end{array}$ & \\
\hline $\begin{array}{l}\text { Baseline (- } \\
500-0 \mathrm{~ms})\end{array}$ & $\begin{array}{l}\text { Proportion of looks } \\
\text { to animates }\end{array}$ & $\begin{array}{l}\text { Main of Prime } \\
\text { Type }\end{array}$ & $.02 *$ & $.03 *$ & Discourse priming \\
\hline
\end{tabular}




\begin{tabular}{|c|c|c|c|c|c|}
\hline $\begin{array}{l}\text { N1 window } \\
(400-800 \\
\text { ms) }\end{array}$ & $\begin{array}{l}\text { Proportion of } \\
\text { switches to target } \\
\text { (animate or } \\
\text { inanimate) }\end{array}$ & $\begin{array}{l}\text { Prime Type by } \\
\text { Target Type } \\
\text { interaction }\end{array}$ & .09 & $.01 *$ & $\begin{array}{l}\text { Integration of first } \\
\text { post-verbal } \\
\text { argument }\end{array}$ \\
\hline $\begin{array}{l}\text { N1 window } \\
(400-800 \\
\text { ms) }\end{array}$ & $\begin{array}{l}\text { Proportion of } \\
\text { switches to target } \\
\text { (animate or } \\
\text { inanimate) }\end{array}$ & $\begin{array}{l}\text { Verb Match by } \\
\text { Target Type } \\
\text { interaction }\end{array}$ & ns. & $.04 *$ & $\begin{array}{l}\text { No clear theoretical } \\
\text { interpretation }\end{array}$ \\
\hline $\begin{array}{l}\text { N2 window } \\
(0-400 \mathrm{~ms})\end{array}$ & $\begin{array}{l}\text { Proportion of } \\
\text { switches to target } \\
\text { (animate or } \\
\text { inanimate) }\end{array}$ & $\begin{array}{l}\text { Prime Type by } \\
\text { Target Type } \\
\text { interaction }\end{array}$ & $.01 *$ & $.02 *$ & $\begin{array}{l}\text { Integration of } \\
\text { second post-verbal } \\
\text { argument }\end{array}$ \\
\hline
\end{tabular}

\section{Discussion}

The present experiment was designed to improve upon weaknesses in two past visual-world eyetracking studies that used similar paradigms but yielded different results: Arai et al. (2007) and Thothathiri and Snedeker (2008a). Arai et al. (2007) used visual displays that made the message highly predictable. Thothathiri and Snedeker (2008a) used an act-out task that places heavy demands on memory and might result in sub-vocal rehearsal. Abstract priming was found in the latter but not in the former. It's not clear, however, how these design choices contributed to this pattern of results, leaving the question open as to when and under what circumstances abstract priming effects emerge in comprehension. To improve upon this work and constrain our theories of structure building during language comprehension, we performed a visual-world eye-tracking 
study with dative materials closely modeled on those in Thothathiri and Snedeker (2008a) but using a different testing environment and task.

We found and then replicated two different priming effects, neither of which depended upon verb repetition. The first was an information structural priming effect: Participants looked more to the inanimate referents following DO primes and more to the animate referents following PO primes, even prior to the onset of the first post-verbal noun. We interpret this effect as evidence for priming of the event role associated with the sentence-final NP due to the salience of utterance-final information in typical discourse. The second effect was more rapid comprehension of arguments that appeared in their expected positions. Specifically, participants switched to looking at the correct object more reliably for consistent prime-target sequences (i.e., DO-DO, PO-PO) than for inconsistent sequences (i.e., DO-PO, PO-DO). We interpret this effect as evidence that priming eases syntactic processing. However, in these experiments, we found no evidence for prediction of the first post-verbal argument on the basis of syntax, either when the verb was shared across the primes and targets or when it was not (see Fn. 4). Thus, we do not directly replicate the pattern of results in either Arai et al. (2007) or Thothathiri and Snedeker (2008a). We believe this reflects the fact that eye movements during the critical window are being affected by both information structural priming and predictive syntactic priming, two effects which cancel each other out (see below).

These results support the broad conclusion that an act-out task is not necessary for abstract structural priming to occur. Recall that Thothathiri and Snedeker (2008a) used a task which required participants to enact instructions on physical toy objects. Arai et al. (2007), on the other hand, used a passive listening task which required participants only to listen to the sentences and do nothing else. It has been suggested that more active comprehension tasks like 
the act-out task may encourage participants to internally repeat the sentence while performing the task in order to better remember it when they need to act it out (Pickering \& Ferreira, 2008; Pickering, McLean, \& Branigan, 2013; Tooley \& Traxler, 2010; see also Pickering \& Garrod, 2007). This could explain why Thothathiri and Snedeker (2008a) found robust abstract priming while Arai et al. (2007) did not. In our experiments, we used a less active task that did not require participants to interact with the objects and found that priming was as effective when there were different verbs from prime to target as it was when the verb was repeated: Neither the early effect of information structure nor the downstream reactive syntax effect was modulated by verb overlap. Thus, abstract priming effects can emerge in visual-world comprehension in the absence of a demanding physical task.

Nevertheless, our findings do not provide a conclusive answer as to when and under what circumstances abstract priming effects will emerge in comprehension. Although we have shown that abstract priming can emerge absent a demanding physical task, there are still many open possibilities that could explain the broad pattern of results in the literature. Below, we discuss one of these possibilities, suggesting that the types of information comprehenders anticipate in everyday language processing may vary depending on how predictable the meanings are that need to be recovered.

In the remainder of this discussion, we first consider our information structural priming effect in a broad context. We then consider how the multiple levels of linguistic representation that can be primed might interact. Finally, we introduce the hypothesis that priming in comprehension may vary as a function of how deeply, and in what manner, we process sentences as we encounter them. 


\subsection{Priming of information structure}

The information structural effect we found showed up as a tendency for participants to look more to the possible inanimate referents following DO primes and more to the possible animate referents following PO primes. These looks were predictive in that they preceded mention of any of the objects in the display. As noted above, these effects go in the opposite direction of what would be expected on the basis of the syntax of the prime sentences: Had participants been primed by syntax to predict the next argument, then they ought to have looked more to the animate referents following DO primes and to the inanimate referents following PO primes (cf. Arai et al., 2007; Thothathiri \& Snedeker, 2008a). We believe this priming to be due to the different information structures of DO dative and PO dative sentences, though we recognize that this interpretation is post hoc. Thus, while we replicated the pattern itself, our interpretation is tentative.

Given the general tendency for given information to come earlier in sentences and new, focused information to come later (e.g., Gundel, 1988), DO sentences put focus on the theme argument and PO datives put focus on the recipient. If participants built up expectations about the type of information that was going to be new or focused upon hearing the primes, this may have led them to focus on the same kind of information in the targets as well, resulting in the pattern of results we found here. For example, in a DO dative, the privileged sentence-final position is the theme, which is typically inanimate. If a focus on themes was primed, that might lead participants to look more at potential themes on subsequent trials, resulting in more attention to inanimate referents. In contrast, a PO dative emphasizes an animate recipient, therefore encouraging increased attention to animate entities in the display. One potential 
motivation for this increase in attention is the desire to reduce any ambiguity in what the focused entity will be. If that argument is particularly important, resolving it quickly may be imperative. ${ }^{7}$ Information structural priming has been found previously in production in transitive cleft sentences in Dutch (Vernice, Pickering, \& Hartsuiker, 2012) and in passive transitives from German to English (Heydel \& Murray, 2000), Dutch to English (Bernolet, Hartsuiker, \& Pickering, 2009), and Polish to English (Fleischer, Pickering, \& McLean, 2012). For example, Vernice et al. (2012) found that participants were more likely to produce a passive sentence, which topicalizes the patient, following a cleft sentence that emphasizes the patient (Degene die hij slaat is de cowboy "The one who he is hitting is the cowboy") over one that emphasizes the agent (Degene die hem slaat is de cowboy "The one who is hitting him is the cowboy"), even when the surface ordering of arguments is not the same from prime to target (cowboy at the end of the sentence in the prime vs. at the beginning of the sentence in the target). The present study is, to the best of our knowledge, the first reported evidence of information structural priming in datives or in a comprehension task.

Importantly, our information structural priming effect cannot be explained on the basis of lower-level cues, such as the specific identity of the object or animal filling each argument role: In all cases, the nouns used in the two prime sentences for each trial were different from those used in the target sentence. Thus, participants did not simply perseverate on the most recently mentioned noun (the final argument in the second prime sentence). Furthermore, this information structural priming does not seem to be mediated by event similarity: The effect was as large when the verb differed between primes and targets as it was when the verb was the same.

\footnotetext{
${ }^{7}$ We thank an anonymous reviewer for this elegant description of the mechanics of information structural priming.
} 
Instead, participants appear to have been guided by a more generalized binding between thematic roles and focus structure.

One puzzle raised by these results is why we found an effect of information structure in our experiments when neither Arai et al. (2007) nor Thothathiri and Snedeker (2008a) did. We think this has to do with an unintentional feature of our stimuli. In both of these past studies, the target sentences described isolated events or gave instructions, without any unifying discourse features or goals to link the utterances from one trial to the next. In the current study, however, we embedded all of our stimuli — primes, targets, and fillers — within an extended narrative about a single character, John, thus creating a discourse that linked the utterances together. This was done because we anticipated doing a study with children and wanted to make the task more fun for participants, and because we wanted to mask the true goal of the experiment. We suspect that having this coherent story led participants to focus more on the information structure of the sentences as they attempted to integrate each new piece of information into their developing understanding of John.

\subsection{Priming at different levels of representation can interact}

In the present work, we found priming at two distinct levels of linguistic representation: information structure on the one hand and syntactic structure on the other. These findings contribute to a growing literature showing that a variety of representations can be primed, including syntax, semantics, information structure, and mappings between animacy and syntax (e.g., Bock \& Loebell, 1990; Bock, Loebell, \& Morey, 1992; Chang et al., 2003; Hare \& Goldberg, 1999; Vernice et al., 2012; Ziegler \& Snedeker, 2018; Ziegler et al., 2018; for discussion, see Ziegler, Snedeker, \& Wittenberg, 2017). In our paradigm, the two different types 
of priming were detectable at different time points: The informational structural effects occurred at the verb, and the syntactic effects occurred after the nouns could be identified. In contrast, most past work has explored priming during language production, in which the effects of different types of priming are carried on the same measure (production probability) and are revealed by interactions across conditions. For example, as mentioned in the Introduction, Ziegler et al. (2018) found enhanced priming from compositional dative primes ("The boy gives his classmate a pen") to compositional dative targets ("The waitress gives the man a glass") compared with priming from idioms ("The boss gives his employee the boot") or light verb constructions ("The mother gives the child a scolding"). In the first case, both the syntactic and the semantic structures were the same from prime to target, while in the latter case, only the syntactic structure was repeated.

This kind of cumulative priming may help us to understand why priming effects are sometimes absent where we might expect to find them. One possible example of this is studies using shifted datives, in which the relative ordering of the two post-verbal arguments is reversed while the local marking of each argument (with a preposition or case marking) remains intact. In the first study on the priming of shifted datives, Pickering, Branigan, and McLean (2002) found no production priming from shifted POs (e.g., "The racing driver showed to the helpful mechanic the problem with the car") to either standard POs (e.g., "The racing driver showed the torn overall to the manager") or standard DOs (e.g., "The racing driver showed the helpful mechanic the tyre [sic]"). The phrase structure of the shifted PO (NP-V-PP-NP) isn't the same as that of either the standard PO (NP-V-NP-PP) or the standard DO (NP-V-NP-NP), so we should expect no priming on the basis of the syntax. But shifted PO datives express caused motion just as standard PO datives do (cf. caused possession for DO datives; e.g., Goldberg, 1995; Harley, 
2003). This might lead us to expect more standard PO productions than standard DO productions. However, shifted POs are also typically linked to changes in information structure (Arnold, Losongco, Wasow, \& Ginstrom, 2000), and they pattern in this respect with standard DOs rather than standard POs. This might lead us to expect more standard DO productions following shifted PO primes. If these two effects were roughly equal in size, they could cancel each other out. Pickering et al.'s (2002) null results are therefore consistent with these two levels of representation both being primed simultaneously (see also Salamoura \& Williams, 2007; cf. Köhne, Pickering, \& Branigan, 2014; Pappert \& Pechmann, 2014).

The notion of cumulative priming is also relevant to understanding the absence of any predictive syntactic priming in the present study. Unlike Arai et al. (2007) or Thothathiri and Snedeker (2008a), we find no differences at noun onset (see Fn. 4). As we noted above, we suspect that this reflects two forms of priming (information structural and syntactic) that bias looks in the opposite direction converging in the same time window. This provides the simplest explanation for why the information structural effect disappears in this window and why the syntactic effect appears so late relative to other such effects in visual-world paradigm studies.

\subsection{Implications for comprehension priming research}

Our results demonstrate that the act-out task is not necessary for getting abstract priming in the visual-world paradigm. This raises questions of why abstract priming was absent in the Arai et al. (2007) study. While our results cannot resolve this question, we suspect that the critical difference in their experiment was the high predictability of the target sentences. Specifically, as we noted above, after the verb, the visual scenes in the Arai et al. (2007) study were consistent 
with only one ditransitive event, while the scenes in the present study, like those in Thothathiri and Snedeker (2008a), were consistent with ten events.

Thus, one intriguing possibility is that abstract priming doesn't depend on the task but rather on the degree to which fully processing an utterance is needed to determine the speaker's message. When the message is inferable, as in Arai et al. (2007), the conceptual representation may be fully available prior to hearing the sentence. All you need to do, then, is monitor the words as they come in to make sure the lexical content is consistent with this conceptual analysis. Presumably, shallow lexical processing would increase lexicalized but not abstract priming (e.g., Chang et al., 2006; Scheepers et al., 2017). However, if you cannot construct a conceptual representation prior to hearing the sentence, as in Thothathiri and Snedeker (2008a) and in our own study, then you will need to build a syntactic representation of the sentence to link the arguments to their thematic roles. This would presumably result in more robust activation of the syntax, leading to greater abstract priming.

Note that this explanation assumes that there is a stark difference in the predictability of the target sentences in Arai et al. (2007) and Thothathiri and Snedeker (2008a) given the visual displays. To test whether this is true, we conducted a prediction task using the materials from each of these three studies (including our own). We asked 22 native English speakers (12 female, 11 male; mean age $=34, \mathrm{SD}=11$, range $=23-70)$ on Amazon Mechanical Turk to complete each target sentence, given a sentence fragment up to and including the verb (e.g., "Now, he's gonna feed...") and the corresponding visual display. The items consisted of our eight target items and eight of the original targets from both the Arai et al. (2007) and Thothathiri and Snedeker (2008a) studies (selected at random). For our items and those in Arai et al. (2007), we used the original visual displays; for the items in Thothathiri and Snedeker (2008a), each target sentence 
was paired with a reconstruction of the corresponding visual display in a cartoon format. ${ }^{8}$ Each participant in the norming study responded to all 24 items. We coded the response as correct if it included the two correct referents (and no others) and assigned them to the correct roles. In our study, and in Thothathiri and Snedeker (2008a), there were two different events paired with each display depending on whether the target was a DO or a PO (e.g., "Now, he's gonna feed the baby the apple" vs. "Now, he's gonna feed the bagel to the girl"). Thus, to determine predictability, we first coded responses relative to the DO target, and then relative to the PO target. The results were the same, so we just report the first analysis. Participants predicted the correct ditransitive event $78 \%$ percent of the time for the materials in Arai et al. (2007), $15 \%$ of the time for those in Thothathiri and Snedeker (2008a), and 13\% of the time for the present study. This resulted in a reliable difference in predictability between the Arai et al. (2007) study and the other two, $\beta=2.18(\mathrm{SE}=.40), z=5.50, p<.001$, and $\beta=1.92(\mathrm{SE}=.26), z=7.40, p<.001$, respectively, supporting our conjecture..$^{9}$ Follow-up work should use both types of visual displays in the same population to test the message predictability hypothesis introduced above.

We now consider the degree to which this hypothesis is consistent with the broader literature on abstract and lexicalized comprehension priming. Because we are interested specifically in the priming of abstract structure (compared to other possible contributors), we limit this analysis only to studies which compared two prime sentences that conveyed the same approximate message with two distinct syntactic structures. Thus, we include studies on the dative and active-passive alternations (in all languages) and on argument scrambling (in casemarked languages), but we exclude studies of high-low attachment ambiguities, reduced relative-

\footnotetext{
${ }^{8}$ We thank Manabu Arai for providing us with the original Arai et al. (2007) materials.

${ }^{9}$ These analyses included Study (e.g., Arai vs. T\&S) as an effect-coded fixed effect in two separate logistic mixedeffects models (lme4 package) in R, with random intercepts for participant and item and a random slope for Study within participants.
} 
main clause ambiguities, and direct object-sentence complement ambiguities (for a similar analysis, see also Branigan \& Pickering, 2017). By our count, there have been over 50 studies on comprehension priming as of the time of writing, but only 10 involved constructions that met this criterion. These studies are summarized in Table 2. Two of them are the focus of the present work (Arai et al., 2007; Thothathiri \& Snedeker, 2008a), two more did not look for across-verb priming effects (Carminati et al., 2008; Weber \& Indefrey, 2009), and another included passive sentences but didn't look at these constructions separately from the other sentence types in their study (Luka \& Barsalou, 2005). Of the remaining studies, four found abstract priming in datives (Thothathiri \& Snedeker, 2008b), active-passives (Arai \& Mazuka, 2014; Segaert et al., 2013) and scrambled transitives (Scheepers \& Crocker, 2004), and one found only within-verb but not across-verb priming in datives (Tooley \& Bock, 2014).

Table 2. Survey of relevant comprehension priming literature.

\begin{tabular}{|l|l|l|l|l|l|l|}
\hline Study & Age & Language & Structure & Paradigm & Abstract & Notes \\
Scheepers & Adults & German & SVO/OVS & Visual-world & Yes & Target events \\
(2004) & & & transitives & eye tracking & & unpredictable \\
Arai et al. & Adults & English & Datives & Visual-world & No & Target events \\
$(2007)$ & & & & eye tracking & & fully \\
\hline
\end{tabular}




\begin{tabular}{|c|c|c|c|c|c|c|}
\hline $\begin{array}{l}\text { Carminati } \\
\text { et al. } \\
(2008)\end{array}$ & Adults & English & Datives & $\begin{array}{l}\text { Visual-world } \\
\text { eye tracking }\end{array}$ & N/A & \\
\hline $\begin{array}{l}\text { Thothathiri } \\
\& \\
\text { Snedeker } \\
\text { (2008a) }\end{array}$ & Adults & English & Datives & $\begin{array}{l}\text { Visual-world } \\
\text { eye tracking }\end{array}$ & Yes & $\begin{array}{l}\text { Target events } \\
\text { unpredictable }\end{array}$ \\
\hline $\begin{array}{l}\text { Thothathiri } \\
\& \\
\text { Snedeker } \\
(2008 b)\end{array}$ & Children & English & Datives & $\begin{array}{l}\text { Visual-world } \\
\text { eye tracking }\end{array}$ & Yes & $\begin{array}{l}\text { Target events } \\
\text { unpredictable }\end{array}$ \\
\hline $\begin{array}{l}\text { Arai \& } \\
\text { Mazuka } \\
\text { (2014) }\end{array}$ & Children & Japanese & Passives & $\begin{array}{l}\text { Visual-world } \\
\text { eye tracking }\end{array}$ & Yes & $\begin{array}{l}\text { Target events } \\
\text { unpredictable }\end{array}$ \\
\hline $\begin{array}{l}\text { Luka \& } \\
\text { Barsalou } \\
\text { (2005) }\end{array}$ & Adults & English & $\begin{array}{l}\text { Some } \\
\text { passives, } \\
\text { among } \\
\text { others }\end{array}$ & $\begin{array}{l}\text { Acceptability } \\
\text { judgments }\end{array}$ & $\begin{array}{l}\text { Yes (but } \\
\text { includes } \\
\text { non- } \\
\text { alternators) }\end{array}$ & $\begin{array}{l}\text { No separate } \\
\text { analysis for } \\
\text { passives }\end{array}$ \\
\hline $\begin{array}{l}\text { Weber \& } \\
\text { Indefrey } \\
\text { (2009) }\end{array}$ & Adults & $\begin{array}{l}\text { German- } \\
\text { to- } \\
\text { English, } \\
\text { English- } \\
\text { to-English }\end{array}$ & Passives & $\begin{array}{l}\text { fMRI } \\
\text { repetition } \\
\text { suppression, } \\
\text { self-paced } \\
\text { reading }\end{array}$ & N/A & \\
\hline
\end{tabular}




\begin{tabular}{|l|l|l|l|l|l|l|}
\hline Segaert et & Adults & Dutch & Passives & fMRI & Yes & Target events \\
Bock & & & & repetition & & unpredictable \\
Tooley \& & Adults & English & Datives & Self-paced & No & Target events \\
\hline
\end{tabular}

The message predictability hypothesis correctly predicts the priming pattern for four of the five studies. Thothathiri and Snedeker (2008b) used the same kind of open-ended displays as Thothathiri and Snedeker (2008a), with children, and found robust abstract priming. Both Arai and Mazuka (2014) and Scheepers and Crocker (2004) used static pictures depicting events, like Arai et al. (2007). However, in contrast with Arai et al. (2007), the pictures in Arai and Mazuka (2014) and Scheepers and Crocker (2004) were designed to depict two distinct transitive events with overlapping participants (e.g., a nurse simultaneously blow-drying a priest and being pushed by a sportsman). Thus, the speaker's message could not be inferred prior to assigning at least one noun to its role. Both of these studies found abstract priming. In contrast, the design in Tooley and Bock (2014) was such that participants had already encountered each target sentence prior to being tested on it in a self-paced reading procedure (with a distractor task in between). Thus, the message of the sentence was completely predictable, and participants showed no robust across-verb priming in datives. ${ }^{10}$

\footnotetext{
10 Tooley and Bock (2014) included two types of dative sentences: to-datives (e.g., "The widow gave the Mercedes to the church") and for-datives (e.g., "The stock broker bought a Rolls Royce for his mistress"). The authors note that, when divided up, to-datives appear to have led to abstract priming while for-datives did not. However, no statistics were provided on this analysis, and we therefore cannot conclude that any significant priming occurred.
} 
The message predictability hypothesis is not transparently consistent with the fifth study, however. Segaert et al. (2013) did find abstract priming in Dutch passives, despite the target events being entirely predictable (participants saw an image of the event for up to a full second before hearing the event described). This divergent finding could reflect the nature of the dependent measure. Segaert et al. (2013) found repetition suppression in fMRI, such that target sentences that matched the structure of the primes elicited significantly less neural activity than those that differed in structure. Perhaps neural activity is a more sensitive measure of linguistic similarity, allowing it to pick up on subtler differences in structure that may get washed out in our behavioral measures.

In summary, abstract priming effects are consistently observed when the message is unpredictable and comprehenders must link each argument to its thematic role by way of the syntax. When the message is fully predictable, abstract priming is sometimes but not always absent. This suggests that varying the predictability of the message within a single experiment could provide useful information on how processing changes depending on the goals of comprehension.

\subsection{Towards a flexibly adaptive view of language comprehension}

Broadly speaking, our results are consistent with a view of language comprehension that treats it as a hierarchical, dynamic, and actively generative process, the goal of which is to arrive at a message-level representation at a rate that allows one to keep up with the speed of the unfolding linguistic signal (e.g., Farmer, Brown, \& Tanenhaus, 2013; Kuperberg \& Jaeger, 2015; Kutas, DeLong, \& Smith, 2011; Pickering \& Garrod, 2007, 2013). This goal is achieved by building higher-level representations consistent with each incoming word and in turn using these higher- 
level representations to constrain expectations of subsequent inputs at lower levels. How well such input is predicted will affect the ease with which it gets integrated into the developing higher-level representations - the better predicted, the easier the uptake. Thus, prediction in this sense plays a pivotal role in driving higher-level inference within the time constraints of typical speech rates.

Critically, within this type of framework, multiple levels of representation are built and/or updated simultaneously, each of which can generate (logically) independent predictions about upcoming information. In many cases, such predictions might move in the same direction (e.g., predictions based on lexicalized vs. abstract syntactic structure), while in others, they may compete (e.g., predictions based on abstract syntax vs. information structure). Which representation wins out, if any, will thus depend on the relative strength of the predictions as well as their relevance in a particular context at a given time, among other possible factors.

Both of the effects we found fit within this view of language comprehension. First, our information structural effects demonstrate that participants used the focus structure of the prime sentences to predict the type of information that would be focused in the target sentence, leading them to fixate the relevant quadrant images in an attempt to better disambiguate the upcoming referent. Second, our downstream syntactic integration effects demonstrate that participants also used the syntactic structure of the prime sentences to integrate the incoming words in the target sentence, leading them to fixate the intended referents more reliably when the target matched the predicted structure (i.e., DO target following DO prime or PO target following PO prime) than when it did not. Thus, participants used information in the preceding sentences to constrain their interpretations of the incoming linguistic signal. 
We have suggested that one possible reason for why Arai et al. (2007) found no abstract priming while Thothathiri and Snedeker (2008a) and our own study did has to do with the fact that the target sentences in Arai et al. (2007) were completely predictable from the visual displays whereas the target sentences in our study and in Thothathiri and Snedeker (2008a) were not. This suggestion is readily integrated with the adaptive view of comprehension introduced above. Specifically, within this framework, the goal of language comprehension is to arrive at a message-level representation of the unfolding linguistic material quickly and efficiently. When this message-level representation is already known, this reduces the burden on the comprehender such that she need only verify that the incoming words generally match this representation, freeing up cognitive resources for other tasks (like wondering when the study will end). When the message is not known, however, intermediate-level representations (like syntactic structures and thematic grids) need to be fully constructed and maintained in order for the message to be reconstructed. Treating language comprehension as a dynamic and generative process points us toward an account of how comprehension changes depending on the situational demands and context.

\section{Conclusion}

In this paper, we investigated comprehension priming in the visual world using materials modeled after Thothathiri and Snedeker (2008a) but without the problematic act-out task. We found that physical task engagement is not necessary for abstract priming effects to emerge. The abstract priming we observed took two distinct forms: an early effect of information structure and a later, downstream effect of syntax. These results suggest that priming occurs simultaneously at multiple levels of representation, and these different forms of priming can be 
layered in complex ways. This is also, to our knowledge, the first study to find priming at the level of information structure in dative stimuli. Our data have broad implications for theories of language comprehension, as they suggest that the types of structure that people implicitly focus on and use for prediction in everyday language processing can and do vary depending on the context in which comprehension occurs. 


\section{Acknowledgments}

This research was funded in part by the Elsie Hopestill Stimson Fund from Harvard's Psychology Department. Special thanks to the members of SnedLab/Harvard LDS for helpful feedback and discussion; to Brianne Gallagher for stim creation; and to Brianne Gallagher, Jared Hawn, Cara Vincelette, and Jamie Ye for assistance with scheduling and running participants. 


\section{References}

Altmann, G. T. M., \& Kamide, Y. (1999). Incremental interpretation at verbs: Restricting the domain of subsequent reference. Cognition, 73(3), 247-264.

Arai, M., \& Mazuka, R. (2014). The development of Japanese passive syntax as indexed by structural priming in comprehension. The Quarterly Journal of Experimental Psychology, 67(1), 60-78.

Arai, M., Van Gompel, R. P. G., \& Scheepers, C. (2007). Priming ditransitive structures in comprehension. Cognitive Psychology, 54, 218-250.

Arnold, J. E., Losongco, A., Wasow, T., \& Ginstrom, R. (2000). Heaviness vs. newness: The effects of structural complexity and discourse status on constituent ordering. Language, $76(1), 28-55$.

Baayen, R. H., Davidson, D. J., \& Bates, D. M. (2008). Mixed-effects modeling with crossed random effects for subjects and items. Journal of Memory and Language, 59(4), 390-412.

Barr, D. J., Levy, R., Scheepers, C., \& Tily, H. J. (2013). Random effects structure for confirmatory hypothesis testing: Keep it maximal. Journal of Memory and Language, $68(3), 255-278$

Bates, D. M. (2010). lme4: Mixed-effects modeling with R. Available online at http://lme4.rforge.r-project.org/book/.

Bernolet, S., Hartsuiker, R. J., \& Pickering, M. J. (2009). Persistence of emphasis in language production: A cross-linguistic approach. Cognition, 112, 300-317.

Bock, J. K. (1986). Syntactic persistence in language production. Cognitive Psychology, 18, $355-387$. 
Bock, K., \& Ferreira, V. S. (2014). Syntactically speaking. In M. Goldrick, V. S. Ferreira, \& M. Miozzo (Eds.), The Oxford Handbook of Language Production (pp. 21-46). New York, NY: Oxford University Press.

Bock, K., \& Levelt, W. (1994). Language production: Grammatical encoding. In M. A. Gernsbacher (Ed.), Handbook of Psycholinguistics (pp. 945-984). San Diego, CA: Academic Press.

Bock, K., \& Loebell, H. (1990). Framing sentences. Cognition, 35, 1-39.

Bock, K., Loebell, H., \& Morey, R. (1992). From conceptual roles to structural relations: Bridging the syntactic cleft. Psychological Review, 99, 150-171.

Branigan, H. P. (2007). Syntactic priming. Language and Linguistics Compass, 1(1-2), 1-16. Branigan, H. P., \& Pickering, M. J. (2017). An experimental approach to linguistic representation. Behavioral and Brain Sciences, 40, 1-61.

Branigan, H. P., Pickering, M. J., Liversedge, S. P., Stewart, A. J., \& Urbach, T. P. (1995). Syntactic priming: Investigating the mental representations of language. Journal of Psycholinguistic Research, 24(6), 489-506.

Branigan, H. P., Pickering, M. J., \& McLean, J. F. (2005). Priming prepositional-phrase attachment during comprehension. Journal of Experimental Psychology: Learning, Memory \& Cognition, 31(3), 468-481.

Carminati, M. N., van Gompel, R. P. G., Scheepers, C., \& Arai, M. (2008). Syntactic priming in comprehension: The role of argument order and animacy. Journal of Experimental Psychology: Learning, Memory, and Cognition, 34(5), 1098-1110.

Chang, F., Bock, K., \& Goldberg, A. E. (2003). Can thematic roles leave traces of their places? Cognition, 90, 29-49. 
Chang, F., Dell, G. S., \& Bock, K. (2006). Becoming syntactic. Psychological Review, 113(2), 234-272.

Cleland, A. A., \& Pickering, M. J. (2003). The use of lexical and syntactic information in language production: Evidence from the priming of noun-phrase structure. Journal of Memory and Language, 49, 214-230.

Cooper, R. M. (1974). The control of eye fixation by the meaning of spoken language: A new methodology for real-time investigation of speech, perception, memory, and language processing. Cognitive Psychology, 6(1), 84-107.

Deese, J., \& Kaufman, R. A. (1957). Serial effects in recall of unorganized and sequentially organized verbal material. Journal of Experimental Psychology, 54(3), 180-187.

Dowty, D. (1991). Thematic proto-roles and argument selection. Language, 67(3), 547-619.

Farmer, T. A., Brown, M. \& Tanenhaus, M. K. (2013). Prediction, explanation, and the role of generative models in language processing (commentary on Clark's "Whatever next? Predictive brains, situated agents, and the future of cognitive science"). Brain and Behavioral Sciences, 36(3), 211-212.

Fernald, A., Zangl, R., Portillo, A. L., \& Marchman, V. A. (2008). Looking while listening: Using eye movements to monitor spoen language comprehension by infants and young children. In I. A. Sekerina, E. M. Fernández, \& H. Clahsen (Eds.), Developmental Psycholinguistics: On-line Methods in Children's Language Processing (pp. 97-135). Amsterdam: John Benjamins.

Ferreira, F., Bailey, K. G. D., \& Ferraro, V. (2002). Good-enough representations in language comprehension. Current Directions in Psychological Science, 11(1), 11-15. 
Fleischer, Z., Pickering, M. J., \& McLean, J. F. (2012). Shared information structure: Evidence from cross-linguistic priming. Bilingualism: Language and Cognition, 15, 568-579.

Garrett, M. F. (1980). Levels of processing in sentence production. In B. Butterworth (Ed.), Language Production (Vol. 1, pp. 177-220). London, UK: Academic Press.

Goldberg, A. E. (1995). Constructions: A construction grammar approach to argument structure. Chicago, IL: University of Chicago Press.

Gundel, J. K. (1988). Universals of topic-comment structure. Studies in Syntactic Typology, 17, 209-239.

Hale, J. (2001). A probabilistic early parser as a psycholinguistic model. In XX (Eds.), Proceedings of the 2nd Meeting of the North American Chapter of the Association for Computational Linguistics (pp. 159-166). Stroudsburg, PA: Association for Computational Linguistics.

Hare, M. L., \& Goldberg, A. E. (1999). Structural priming: Purely syntactic? In M. Hahn \& S. C. Stones (Eds.), Proceedings of the 21st Annual Meeting of the Cognitive Science Society (pp. 208-211). Mahwah, NJ: Erlbaum.

Harley, H. (2003). Possession and the double object construction. In P. Pica (Ed.), Linguistic Variation Yearbook, Vol. 2 (pp. 31-70). Amsterdam: John Benjamins.

Heydel, M., \& Murray, W. S. (2000). Conceptual effects in sentence priming: A cross-linguistic perspective. In M. De Vincenzi \& V. Lombardo (Eds.), Cross-linguistic Perspectives on Language Processing (pp. 227-254). Dordrecht: Springer.

Jaeger, T. F. (2008). Categorical data analysis: Away from ANOVAs (transformation or not) and towards logit mixed models. Journal of Memory and Language, 59(4), 434-446. 
Köhne, J., Pickering, M. J., \& Branigan, H. P. (2014). The relationship between sentence meaning and word order: Evidence from structural priming in German. The Quarterly Journal of Experimental Psychology, 67(2), 304-318.

Kuperberg, G. R., \& Jaeger, T. F. (2015). What do we mean by prediction in language comprehension? Language, Cognition, and Neuroscience, 31(1), 32-59.

Kutas, M., DeLong, K. A., \& Smith N. J. (2011). A look around at what lies ahead: Prediction and predictability in language processing. In M. Bar (Ed.), Predictions in the Brain: Using Our Past to Generate a Future (pp. 190-207). Oxford, UK: Oxford University Press.

Levelt, W. J. M. (1989). Speaking: From intention to articulation. Cambridge, MA: MIT Press.

Levin, B., \& Rappaport Hovav, M. (2005). Argument realization. Cambridge: Cambridge University Press.

Levy, R. (2008a). Expectation-based syntactic comprehension. Cognition, 106, 1126-1177.

Levy, R. (2008b). A noisy-channel model of human sentence comprehension under uncertain input. In Proceedings of the 2008 Conference on Empirical Methods in Natural Language Processing (pp. 234-243). Stroudsburg, PA: Association for Computational Linguistics.

Levy, R. (2011). Integrating surprisal and uncertain-input models in online sentence comprehension: Formal techniques and empirical results. In Proceedings of the 49th Annual Meeting of the Association for Computational Linguistics (pp. 1055-1065). Stroudsburg, PA: Association for Computational Linguistics. 
Luka, B. J., \& Barsalou, L. W. (2005). Structural facilitation: Mere exposure effects for grammatical acceptability as evidence for syntactic priming in comprehension. Journal of Memory and Language, 52, 436-459.

MacDonald, M. C., Pearlmutter, N. J., \& Seidenberg, M. S. (1994). The lexical nature of syntactic ambiguity resolution. Psychological Review, 101, 676-703.

Mahowald, K., James, A., Futrell, R., \& Gibson, E. (2016). A meta-analysis of syntactic priming in language production. Journal of Memory and Language, 91, 5-27. http://dx.doi.org/10.1016/j.jml.2016.03.009

Matin, E., Shao, K. C., \& Boff, K. R. (1993). Saccadic overhead: Information-processing time with and without saccades. Perception and Psychophysics, 53, 372-380.

Morgan, E., Keller, F., and Steedman, M. (2010). A bottom-up parsing model of local coherence effects. In S. Ohlsson \& R. Catrambone (Eds.), Proceedings of the 32nd Annual Conference of the Cognitive Science Society (pp. 1559-1564). Austin, TX: Cognitive Science Society.

Pappert, S., \& Pechmann, T. (2014). Priming word order by thematic roles: No evidence for an additional involvement of phrase structure. The Quarterly Journal of Experimental Psychology, 67(11), 2260-2278.

Pickering, M. J., \& Branigan, H. P. (1998). The representation of verbs: Evidence from syntactic priming in language production. Journal of Memory and Language, 39, 633-651.

Pickering, M. J., Branigan, H. P., \& McLean, J. F. (2002). Constituent structure is formulated in one stage. Journal of Memory and Language, 46, 586-605.

Pickering, M. J., \& Ferreira, V. S. (2008) Structural priming: A critical review. Psychological Bulletin, 134(3), 427-459. 
Pickering, M. J., \& Garrod, S. (2007). Do people use language production to make predictions during comprehension? Trends in Cognitive Sciences, 11, 105-110.

Pickering, M. J., \& Garrod, S. (2013). An integrated theory of language production and comprehension. Behavioral and Brain Sciences, 36(4), 329-347.

Pickering, M. J., McLean, J. F., \& Branigan, H. P. (2013). Persistent structural priming and frequency effects during comprehension. Journal of Experimental Psychology: Learning, Memory, and Cognition, 39, 890-897.

Quirk, R., Greenbaum, S., Leech, G., \& Svartvik, J. (1972). A grammar of contemporary English. London: Longman.

Salamoura, A, \& Williams, J. N. (2007). Processing verb argument structure across languages: Evidence for shared representations in the bilingual lexicon. Applied Psycholinguistics, $28,627-660$.

Scheepers, C., \& Crocker, M. W. (2004). Constituent order priming from reading to listening: A visual- world study. In M. Carreiras \& C. J. Clifton (Eds.), The On-line Study of Sentence Comprehension: Eyetracking, ERPs, and Beyond (pp. 167-185). Hove: Psychology Press.

Scheepers, C., Raffray, C. N., \& Myachykov, A. (2017). The lexical boost effect is not diagnostic of lexically-specific syntactic representations. Journal of Memory and Language, 95, 102-115.

Segaert, K., Kempen, G., Petersoon, K. M., \& Hagoort, P. (2013). Syntactic priming and the lexical boost effect during sentence production and sentence comprehension: An fMRI study. Brain and Language, 124, 174-183. 
Tabor, W., Galantucci, B., \& Richardson, D. (2004). Effects of merely local syntactic coherence on sentence processing. Journal of Memory and Language, 50, 355-370.

Tanenhaus, M. K., Spivey-Knowlton, M. J., Eberhard, K. M., \& Sedivy, J. C. (1995). Integration of visual and linguistic information in spoken language comprehension. Science, 268, 1632-1634.

Thothathiri, M., \& Snedeker, J. (2008a). Give and take: Syntactic priming during spoken language comprehension. Cognition, 108(1), 51-68.

Thothathiri, M., \& Snedeker, J. (2008b). Syntactic priming during language comprehension in three- and four-year-old children. Journal of Memory and Language, 58, 188-213.

Tooley, K. M., \& Bock, K. (2014). On the parity of structural persistence in language production and comprehension. Cognition, 132, 101-136.

Tooley, K. M., \& Traxler, M. J. (2010). Syntactic priming effects in comprehension: A critical review. Language and Linguistics Compass, 4(10), 925-937.

Tooley, K. M., Traxler, M. J., \& Swaab, T. Y. (2009). Electrophysiological and behavioral evidence of syntactic priming in sentence comprehension. Journal of Experimental Psychology: Learning, Memory, and Cognition, 35(1), 19-45.

Townsend, D. J., \& Bever, T. G. (2001). Sentence comprehension: The integration of habits and rules. Cambridge, MA: MIT Press.

Traxler, M. J., \& Tooley, K. M. (2008). Priming in sentence comprehension: Strategic or syntactic? Language and Cognitive Processes, 23(5), 609-645.

Traxler, M. J., \& Tooley, K. M. (2012). Lexical and syntactic priming in language comprehension. In N. Hsu \& Z. Schutt (Eds.), Psychology of Priming (pp. 79-100). Hauppauge, NY: Nova Science Publishers, Inc. 
Trueswell, J. C., \& Tanenhaus, M. K. (1994). Toward a lexicalist framework for constraint-based syntactic ambiguity resolution. In C. Clifton, L. Frazier, \& K. Rayner (Eds.), Perspectives on Sentence Processing (pp. 155-179). Hillsdale, NJ: Lawrence Erlbaum Associates.

Vernice, M., Pickering, M. J., \& Hartsuiker, R. J. (2012). Thematic emphasis in language production. Language and Cognitive Processes, 27(5), 631-664.

Weber, K., \& Indefrey, P. (2009). Syntactic priming in German-English bilinguals during sentence comprehension. NeuroImage, 46, 1164-1172.

Ziegler, J., \& Snedeker, J. (2018). How broad are thematic roles? Evidence from structural priming. Cognition, 179, 221-240.

Ziegler, J., Snedeker, J., \& Wittenberg, E. (2017). Priming is swell, but it's far from simple (commentary on Branigan \& Pickering’s “An experimental approach to linguistic representation"). Behavioral and Brain Sciences, 40, 44-45.

Ziegler, J., Snedeker, J., \& Wittenberg, E. (2018). Event structures drive semantic structural priming, not thematic roles: Evidence form idioms and light verbs. Cognitive Science. 